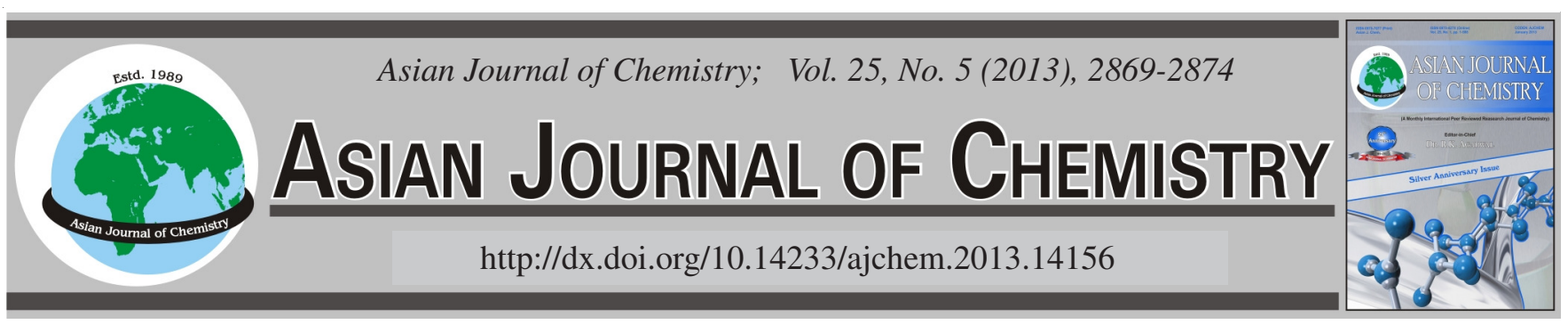

\title{
Comparative Study of Ethylene Catalytic Aromatization and Adsorption Onto Two Kinds of Molecular Sieves
}

\author{
Xiaodong Ma, Feng Ouyang ${ }^{*}$, Dongmei Shen and Xiaokai Cao
}

Environmental Science and Engineering Research Center, Shenzhen Graduate School, Harbin Institute of Technology, Shenzhen 518055, P.R. China *Corresponding author: Fax: +86 755 26033472; Tel: +86 755 26033472; E-mail: ouyangfh@hit.edu.cn; mxdxz@foxmail.com

The catalytic aromatization and adsorption of ethylene onto two kinds of molecular sieves was investigated at different temperatures. The adsorption amount of ethylene did not decrease with the increasing temperature all the time. By in situ FTIR of pyridine adsorption, $\mathrm{NH}_{3-}$ TPD and GC-MS a possible mechanism was proposed. The acid sites of molecular sieves would become the active sites for aromatization of ethylene to improve the adsorption capacity under high temperature. The maximum adsorption amount was proportional to the number of the acid sites activated by high temperature. Final adsorbates were mainly aromatics. The sizes of final products were limited to the diameters of pores.

Key Words: Ethylene, MCM-41, MCM-22, Catalytic aromatization, Adsorption.

\section{INTRODUCTION}

Ethylene, the simplest unsaturated hydrocarbon, is the most produced organic compound and widely used in industry ${ }^{1}$. In 2005, the global production of ethylene exceeded 107 million tons and ethylene was the major chemical produced in all industrial countries ${ }^{2}$. This number is growing larger and larger to meet the increasing demand for ethylene. The excessive emission of ethylene could cause climate change ${ }^{3}$. Long-term exposure to ethylene can make people feel sick. The allowable level for ethylene exposure is $100 \mathrm{mg} / \mathrm{m}^{3}$ in working environments ${ }^{4}$. Ethylene also serves as a hormone in plants ${ }^{5}$. It acts at trace levels throughout the life of the plant. Fruits and vegetables after harvest would release ethylene which can accelerate the maturing of the fruits and enhance them becoming soft ${ }^{6,7}$. Such result increases the difficulty of food preservation.

There are several ways to eliminate ethylene, such as catalytic oxidation $^{8}$, biodegradation ${ }^{9}$, adsorption ${ }^{10}$, photocatalysis $^{11}$, biofiltration ${ }^{12}$, etc. Among these processes, it is believed that the adsorption is one of the best ways referring to the global shortage of resources. The adsorbents are convenient to transfer and place. After adsorption the adsorbates could be reused by desorption. Some studies were carried out for ethylene adsorption using different kinds of adsorbents. Activated carbons ${ }^{13,14}$, Y-type zeolite ${ }^{15,16}$, clinoptilolites ${ }^{17}$, silica gel $^{18}$ and mordenites ${ }^{19}$ are all good adsorbents for ethylene adsorption. Zeolites show excellent potential uses as adsorbents because of its easily controlled and uniformity of pore size, large internal surface area and high thermal and hydrothermal stability. MCM-22 and MCM-41 are common zeolites in practical application. MCM-22 has two independent pore systems. One involves two-dimensional sinusoidal channels $(0.41 \times 0.51$ $\mathrm{nm}$ ) with circular 10-memebered rings. Another consists of 12-membered large cylindrical supercages $(0.71 \times 0.71 \times 1.82$ $\mathrm{nm})^{20}$. MCM-41 possesses hexagonally packed arrays of onedimensional cylindrical pores with large surface area and pore volume $^{21}$. These two kinds of zeolites which differed in pore size and topology will be chosen as our subjects.

Among all the studies of ethylene adsorption, few researches show us the situations when the temperature of adsorption rises. In this study we will show the results of ethylene adsorption at a high temperature and try to reveal the possible mechanism.

\section{EXPERIMENTAL}

Hydrogen form of MCM-22 (denoted as H-MCM-22) with a $\mathrm{Si} / \mathrm{Al}$ ratio equal to 50 , sodium form (denoted as $\mathrm{Na}-$ MCM-41) and hydrogen form (denoted as H-MCM-41) of MCM-41 both with a Si/Al ratio equal to 30 were highly ordered from Novel Chemical Technology Co. Ltd.. Ethylene with the purity of $99.995 \%$, helium and ammonia both with the purity of $99.999 \%$ were provided by Shente Industrial Gases Co. Ltd.. Pyridine of analytical grade was used without further purification. 
The adsorption and desorption isotherms of nitrogen and ethylene were measured using a gas adsorption-desorption measuring apparatus, Belsorp mini II, BEL Japan, Inc. Before measurements, the samples were degased at $673 \mathrm{~K}$ under vacuum (below $1 \mathrm{Kpa}$ ) for $3 \mathrm{~h}$ to clean the surface of the adsorbents. The temperature for nitrogen adsorption-desorption measurements was $77 \mathrm{~K}$. We used Burunauer-EmmettTeller (BET) treatment to get the specific surface area in the $\mathrm{P} / \mathrm{P}_{0}$ range of $0.05-0.3$. The pore size distribution was calculated on the basis of adsorption branches using Barrett-JoynerHalenda (BJH) method and micropore method.

$\mathrm{X}$-ray powder diffraction studies were carried out in the $2 \theta$ range of $1-40^{\circ}$. The data were obtained on a Rigaku D/max $2500 \mathrm{PC}$ with $\mathrm{CuK}_{\alpha 1}$ radiation.

Temperature programmed desorption of ammonia $\left(\mathrm{NH}_{3}-\right.$ TPD) measurements were performed by a modified GC (SP6890) equipped with thermal conductivity detector (TCD). It needed $50 \mathrm{mg}$ samples for each test. The samples were firstly calcined at $823 \mathrm{~K}$ for $3 \mathrm{~h}$ under helium flow. When it returned to the room temperature, the samples adsorbed ammonia for $0.5 \mathrm{~h}$ and then switched back to the helium flow. After the baseline of the thermal conductivity detector signal gone flat at $393 \mathrm{~K}$, the spectrum was finally taken. The desorption temperature was programmed from $393 \mathrm{~K}$ to $893 \mathrm{~K}$ at a rate of $15 \mathrm{~K} / \mathrm{min}$.

Fourier transform infrared spectroscopy (FTIR) spectra of pyridine adsorption were recorded by a Thermo Nicolet 380 spectrometer (USA) with a resolution of $4 \mathrm{~cm}^{-1}$. The adsorbents were made into self-supporting wafers and putted into an in situ FTIR quartz cell. The quartz cell contained heating, cooling and gas flow controlling systems. The pellet made by pure samples was heated firstly at $673 \mathrm{~K}$ for $12 \mathrm{~h}$ under a vacuum of $1.33 \times 10^{-2} \mathrm{~Pa}$ and then cooled to room temperature. After the adsorption of pyridine for $1 \mathrm{~h}$, the quartz cell was vacuumed again to a pressure of $1.33 \times 10^{-2} \mathrm{~Pa}$ for 12 $\mathrm{h}$. The spectrum was recorded at room temperature at first. Then the adsorbents were subjected to thermal treatment at $473 \mathrm{~K}, 576 \mathrm{~K}$ and $673 \mathrm{~K}$ and the spectra were recorded.

Gas chromatography and mass spectrometer (GC-MS) analysis was performed on a Finnigan TRACE DSQ GC/MS, Thermo, USA. The GC 2000 equipped with a $30 \mathrm{~m} \times 0.25 \mathrm{~mm}$ capillary column with a $0.25 \mu \mathrm{m}$ film thickness (DB-17MS, Aglilent, USA). The injector temperature was $573 \mathrm{~K}$. The GC oven was programmed firstly from 313 to $333 \mathrm{~K}$ at a rate of 2 $\mathrm{K} / \mathrm{min}$, secondly to $423 \mathrm{~K}$ at $5 \mathrm{~K} / \mathrm{min}$, finally to $523 \mathrm{~K}$ at $10 \mathrm{~K} /$ $\mathrm{min}$. The mass spectrometer was operated with an ionization voltage of $70 \mathrm{eV}$ and an ion source temperature of $523 \mathrm{~K}$.

\section{RESULTS AND DISCUSSION}

Characterization of the adsorbents: The adsorbents were firstly characterized by XRD. Fig. 1a shows the typical XRD pattern of MCM-22. The peaks of all the crystal planes confirmed the long-range ordering and the framework of MCM-22 20,22. From Fig $1 \mathrm{~b}$ and $1 \mathrm{c}$ we can observe that there is no obvious difference between H-MCM-41 and Na-MCM41. They all presented the (100), (110) and (200) crystal planes, which revealed the hexagonal symmetry of MCM- $41^{23}$.

Fig. 2 depicts the $\mathrm{N}_{2}$ adsorption and desorption isotherms of the three adsorbents. At low pressure (about $\mathrm{P} / \mathrm{P} 0<0.05$ ), micropore filling occurred for every adsorbent. So adsorption amount of $\mathrm{N}_{2}$ all increased sharply at first. Then only MCM41 showed the second leap at the middle range of pressure which was caused by adsorption in mesopores. At around 1 atmospheric pressure, all curves rose up again because of the adsorption in macropores formed by the gaps between the sample powders. The hysteresis loops caused by capillary condensation demonstrated the mesoporous structure of MCM41 in the $\mathrm{P} / \mathrm{P}_{0}$ range of $0.4-0.7$ shown in Fig. $2 \mathrm{~b}$ and 2c. Fig. 3 displays the pore size distributions of samples. As shown in Fig. 3a, the pore size of H-MCM-22 mainly distributes in the range of 0.4-0.7 nm, relatively concentrated. This result also explained why the adsorption amount barely increased after the micropore filling for H-MCM-22. On the other hand, both of the two kinds of MCM-41 had a larger range of pore size distribution (1.2-3 nm) than MCM-22. Some main physical properties are summarized in Table-1.

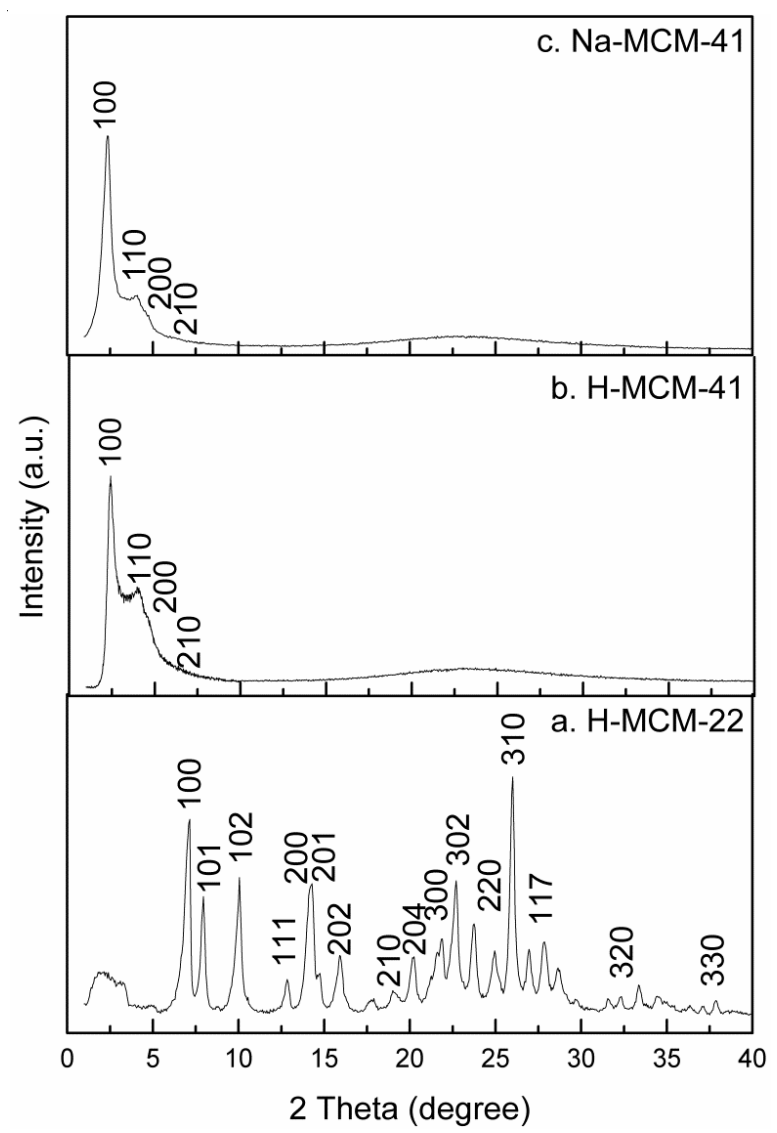

Fig. 1. XRD patterns of (a) H-MCM-22, (b) H-MCM-41and (c) NaMCM-41

Adsorption and desorption measurements of ethylene: The adsorption and desorption measurements of ethylene were carried out at room temperature nearby $(308 \mathrm{~K})$ in the first place. As shown in Fig. 4, H-MCM-41 and Na-MCM-41 has the same adsorption capacity for ethylene at $308 \mathrm{~K}$. (The isotherms of Na-MCM-41 and H-MCM-22 were elevated vertically for convenient observance). While H-MCM-22 had a better performance in ethylene adsorption than MCM-41. Because of the interaction between $\pi$-electron of the $\mathrm{C}=\mathrm{C}$ bonds and acid sites, the isotherms of ethylene desorption presented hysteresis to a certain extent. In the case of H-MCM- 
22 , it was more obvious than MCM-41 because of the strong acidity of H-MCM-22.

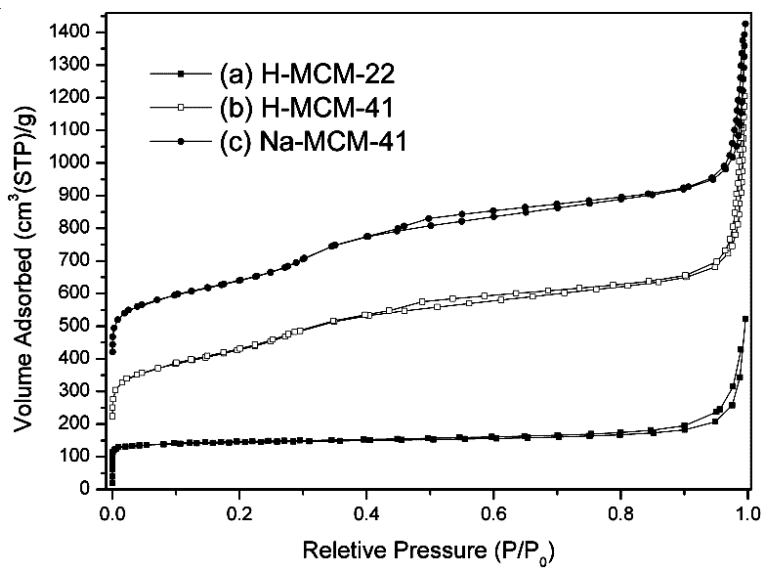

Fig. 2. $\mathrm{N}_{2}$ adsorption and desorption isotherms at $77 \mathrm{~K}$ on (a) H-MCM-22, (b) H-MCM-41 and (c) Na-MCM-41

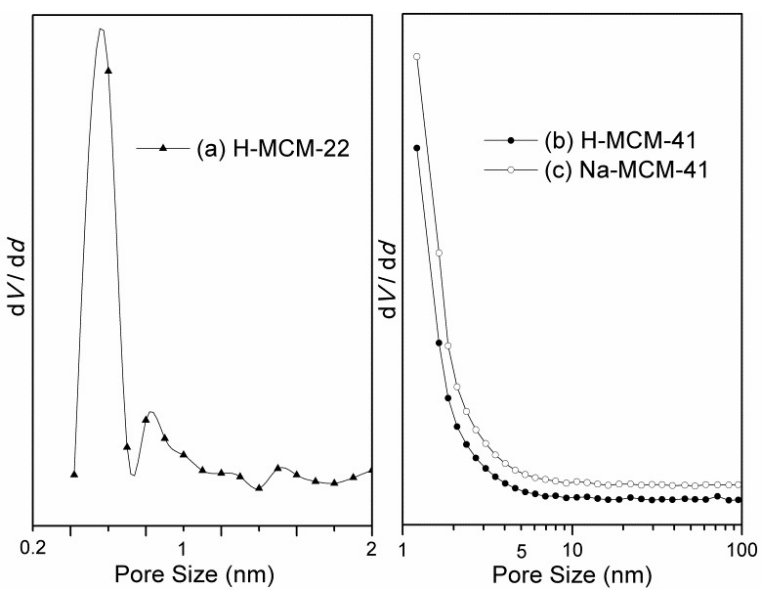

Fig. 3. Pore size distributions of (a) H-MCM-22, calculated by MP method; (b) H-MCM-41 and (c) Na-MCM-41, calculated by BJH method

\begin{tabular}{ccccc}
\multicolumn{7}{c}{ TABLE-1 } \\
\multicolumn{5}{|c}{ MAIN PHYSICAL PROPERTIES OF THE ADSORBENTS } \\
\hline & $\begin{array}{c}\mathrm{S}_{\mathrm{BET}} \\
\left(\mathrm{m}^{2} / \mathrm{g}\right)\end{array}$ & $\begin{array}{c}\mathrm{V}_{\mathrm{t}} \\
(\mathrm{mL} / \mathrm{g})\end{array}$ & $\begin{array}{c}\mathrm{V}_{\text {micro }} \\
(\mathrm{mL} / \mathrm{g})\end{array}$ & $\begin{array}{c}\mathrm{d}_{\text {average }} \\
(\mathrm{nm})\end{array}$ \\
\hline H-MCM-22 & 562 & 0.6115 & 0.2051 & 4.3504 \\
H-MCM-41 & 834 & 1.1220 & 0.5269 & 5.3812 \\
Na-MCM-41 & 885 & 1.1928 & 0.6073 & 5.3883 \\
\hline
\end{tabular}

The isotherms of ethylene adsorption at different temperature were determined in succession. Normally, the adsorption amount would decrease as the increasing temperature. But in our research it showed different trends. All the results are illustrated in Fig. 5. All the data in Fig. 5A were obtained by adsorption measurements at different temperatures. Be pointed out here, the calculation of the adsorption amount should be adjusted when adsorption temperature rose up. The final pressure (around $101 \mathrm{Kpa}$ ) should be filled up by pure ethylene, but actually it wasn't. So we expressed the trend in another way referring to the properties of final products confirmed by GC-MS results. Belsorp mini II could measure the pressure precisely. Certain amount of samples $(0.05 \mathrm{~g})$ was put into the sample cell and pre-treatment was taken. We charged the same sample cell to certain pressure $(70 \mathrm{Kpa})$ at
$303 \mathrm{~K}$. Then the sample was treated under certain temperature. When the pressure stopped altering, we changed the sample temperature to $303 \mathrm{~K}$ and recorded the stable pressure data. Then we could use pressure drop to express the accurate trend of ethylene consumption as shown in Fig. 5B. From Fig. 5A and $5 \mathrm{~B}$ we can conclude that they have the same trend of ethylene adsorption. Below $523 \mathrm{~K}$, the ethylene adsorption of H-MCM-22 increased while MCM-41 decreased as temperature rose. But all the curves showed a downward trend After $623 \mathrm{~K}$. The maximum value of adsorption for MCM-22 appeared at the range of 473 to $523 \mathrm{~K}$. For MCM-41, the maximum adsorption amount appeared at around $623 \mathrm{~K}$.

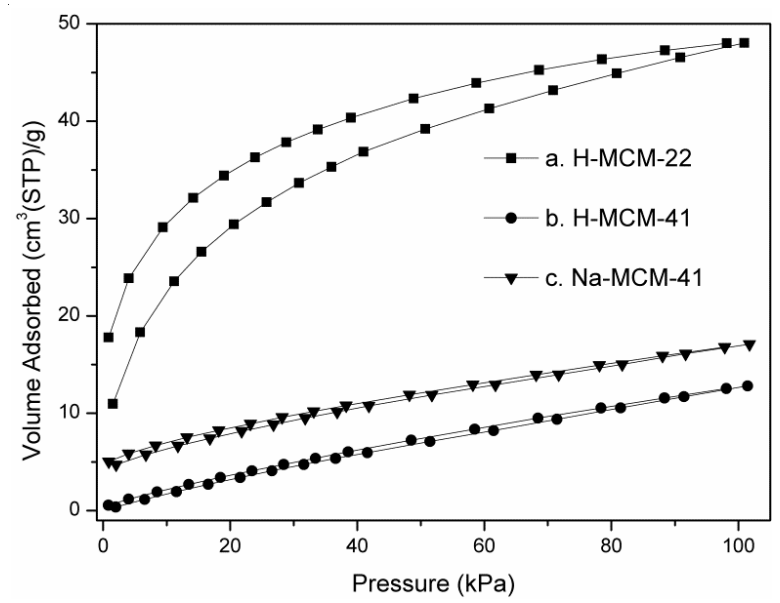

Fig. 4. Ethylene adsorption and desorption isotherms at $308 \mathrm{~K}$ on (a) HMCM-22, (b) H-MCM-41and (c) Na-MCM-41
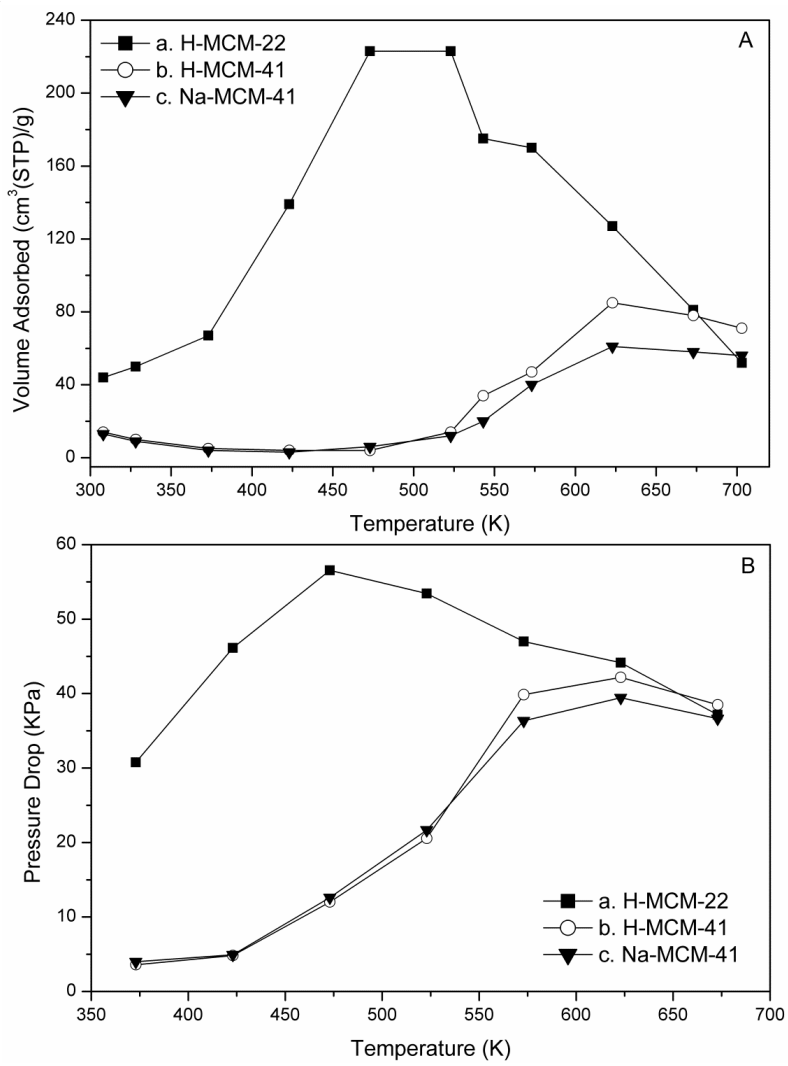

Fig. 5. Trend graph of ethylene adsorption amount on (a) H-MCM-22, (b) H-MCM-41and (c) Na-MCM-41 at different temperature. B was expressed through pressure drop 
Acidity studies: To investigate the acid properties of the adsorbents, we firstly took the FTIR spectra of pyridine adsorption. Figs 6-8 depict the spectra of pyridine adsorption on H-MCM-22, H-MCM-41 and Na-MCM-41 to different thermal treatments. All the bands appeared in the figures were assigned to weak Lewis acid bound pyridine $\left(1575 \mathrm{~cm}^{-1}\right)$, strong Lewis acid bound pyridine (1623 and $1455 \mathrm{~cm}^{-1}$ ), Bronsted acid bound pyridine (1545 and $\left.1636 \mathrm{~cm}^{-1}\right)$, both Bronsted and Lewis acid bound pyridine $\left(1490 \mathrm{~cm}^{-1}\right)$ and hydrogen bonded pyridine (1445 and $\left.1595 \mathrm{~cm}^{-1}\right)^{24}$. The peaks of Lewis acid bound pyridine at $1455 \mathrm{~cm}^{-1}$ and hydrogen bonded pyridine at $1445 \mathrm{~cm}^{-1}$ were difficult to distinguish at room temperature. The bands of hydrogen bonded pyridine disappeared for MCM-41 when the temperature rose to $473 \mathrm{~K}$ and higher temperature. Meanwhile the same band for MCM-22 reduced sharply. The hydrogen bonded pyridine of MCM-22 at 1445 $\mathrm{cm}^{-1}$ was more difficult to desorb than MCM-41. Maybe MCM22 had a stronger hydrogen bond interaction than MCM-41 which attributed to the small pore diameter of MCM-22. Comparing to the room temperature, the Lewis and Bronsted acid bound pyridine both got stronger at higher temperature.

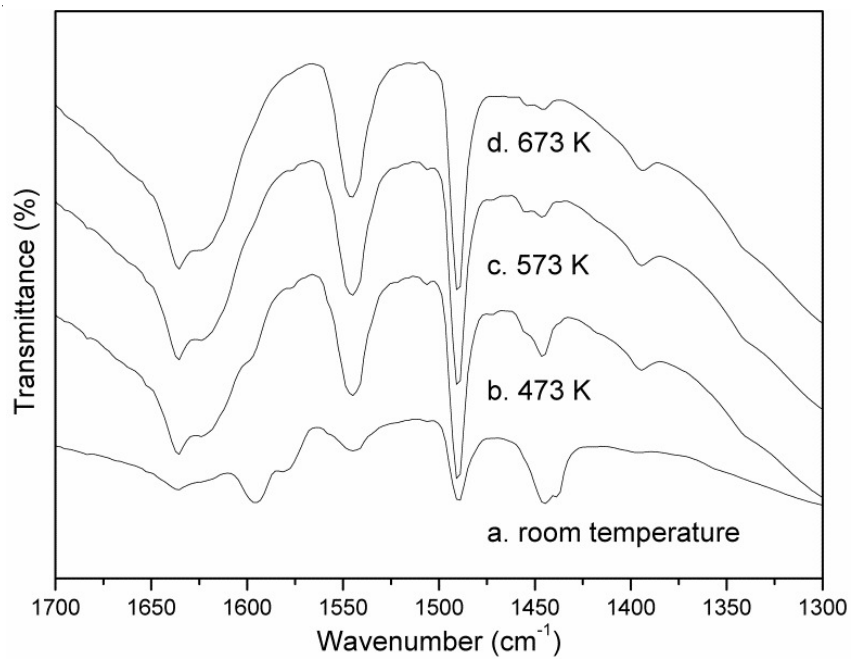

Fig. 6. FTIR spectra of pyridine adsorption on H-MCM-22 at (a) room temperature, (b) $473 \mathrm{~K}$, (c) $573 \mathrm{~K}$ and (d) $673 \mathrm{~K}$

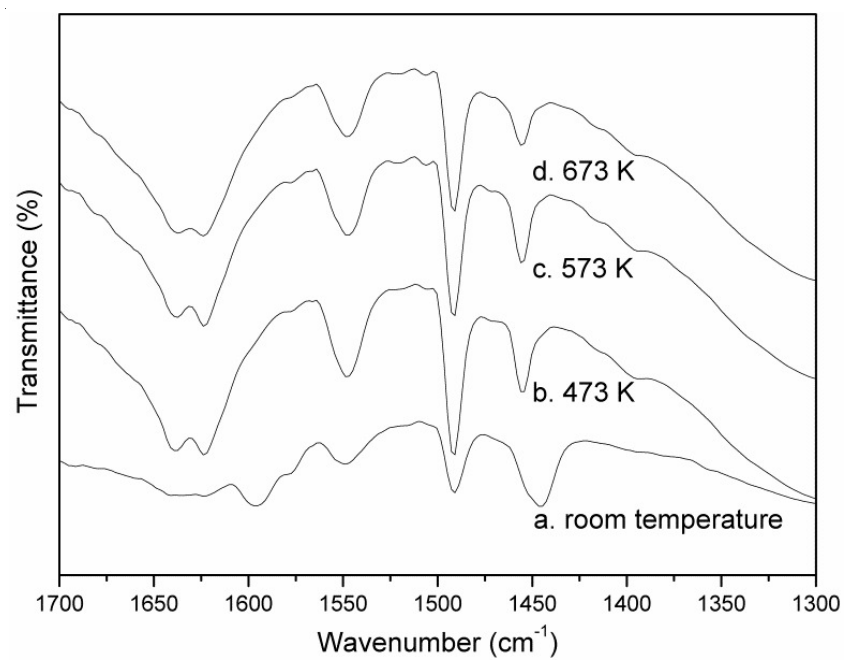

Fig. 7. FTIR spectra of pyridine adsorption on H-MCM-41 at (a) room temperature, (b) $473 \mathrm{~K}$, (c) $573 \mathrm{~K}$ and (d) $673 \mathrm{~K}$

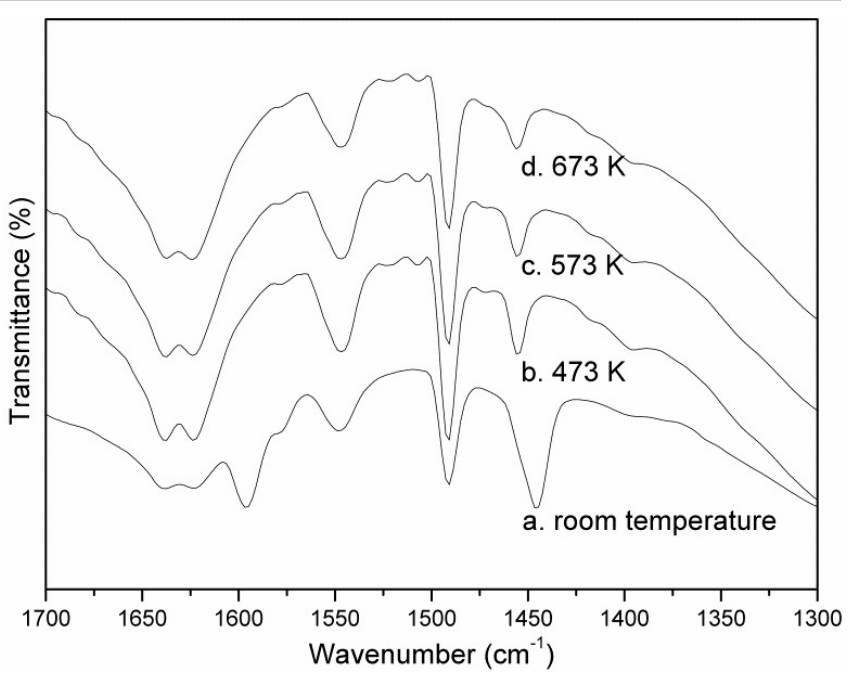

Fig. 8. FTIR spectra of pyridine adsorption on Na-MCM-41 at (a) room temperature, (b) $473 \mathrm{~K}$, (c) $573 \mathrm{~K}$ and (d) $673 \mathrm{~K}$

From the results of FTIR spectra of pyridine adsorption we know that the adsorbents showed great acid properties after thermal activation. But it appeared that they displayed the same nature at different temperature. To investigate the acid strength distribution of the adsorbents, we introduced the $\mathrm{NH}_{3}$-thermal programmed desorption tests. As shown in Fig. 9a, MCM-22 has two kinds of acid center. We believed that the first peak (around $523 \mathrm{~K}$ ) was contributed to the supercages which existed in the pore system of MCM-22. The second peak was due to the other pore system of MCM-22 which contained 10-memebered rings. Fig. 9b and 9c depict the acid strength distribution of H-MCM-41 and Na-MCM-41. The two different types of MCM-41 had the same $\mathrm{Si} / \mathrm{Al}$ ratio, which means they should have the same number of acid sites (If we do not distinguish Lewis acid and Bronsted acid). After the ion exchange of sodium form to hydrogen form, the peak represented the number of the acid sites shifted from 623 to $660 \mathrm{~K}$. It confirmed that H-MCM-41 which possessed more Bronsted acid was stronger in acidity than Na-MCM-41. MCM-41 has a wider range of acid strength distribution than MCM-22 as illustrated in Fig. 9. This result was caused by the broad range of pore size distribution of MCM-41.

GC-MS studies: After the adsorbents reached the maximum adsorption amount and cooled to room temperature, they were transferred into organic solvent immediately. We used $n$-hexane to strip the adsorbates and were analyzed by GC-MS. The results are shown in Figs. 10-12. Among all the measurements, the adsorbates were mainly aromatics. In order of the retention time, the final products ever detected were: dimethylcyclohexane, trimethylcyclohexane, xylene, trimethylbenzene, tetramethylbenzene, pentamethylbenzene, hexamethylbenzene, heptamethylbenzene, octamethylbenzene, nonamethylbenzene, xmethylnaphthalene and their isomers. Cyclohexane was only found in the sample solution of MCM-22. Also no hepta, octa and nona-methylbenzene were found during the test for MCM-22. This process also provided an easy way to collect the final adsorbates and get ready for their future possible reuse.

Possible mechanism: Confirmed by the results of GCMS, we demonstrated that aromatization occurred when the 
temperature rose up during the measurements of ethylene adsorption in this study. The combination of ethylene and proton was the first step during the dimerization of ethylene in acid catalysis and this process needed proton affinity energy ${ }^{25}$. The high temperature gave the energy for aromatization. So the improvement of the adsorption amount could be achieved during our tests.

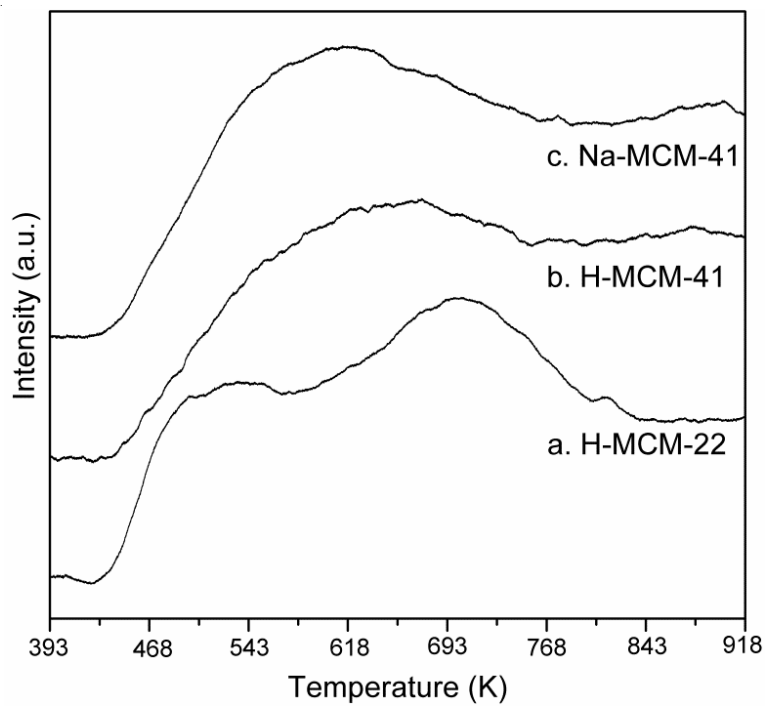

Fig. 9. $\mathrm{NH}_{3}$-TPD spectra of (a) H-MCM-22, (b) H-MCM-41and (c) Na-MCM-41

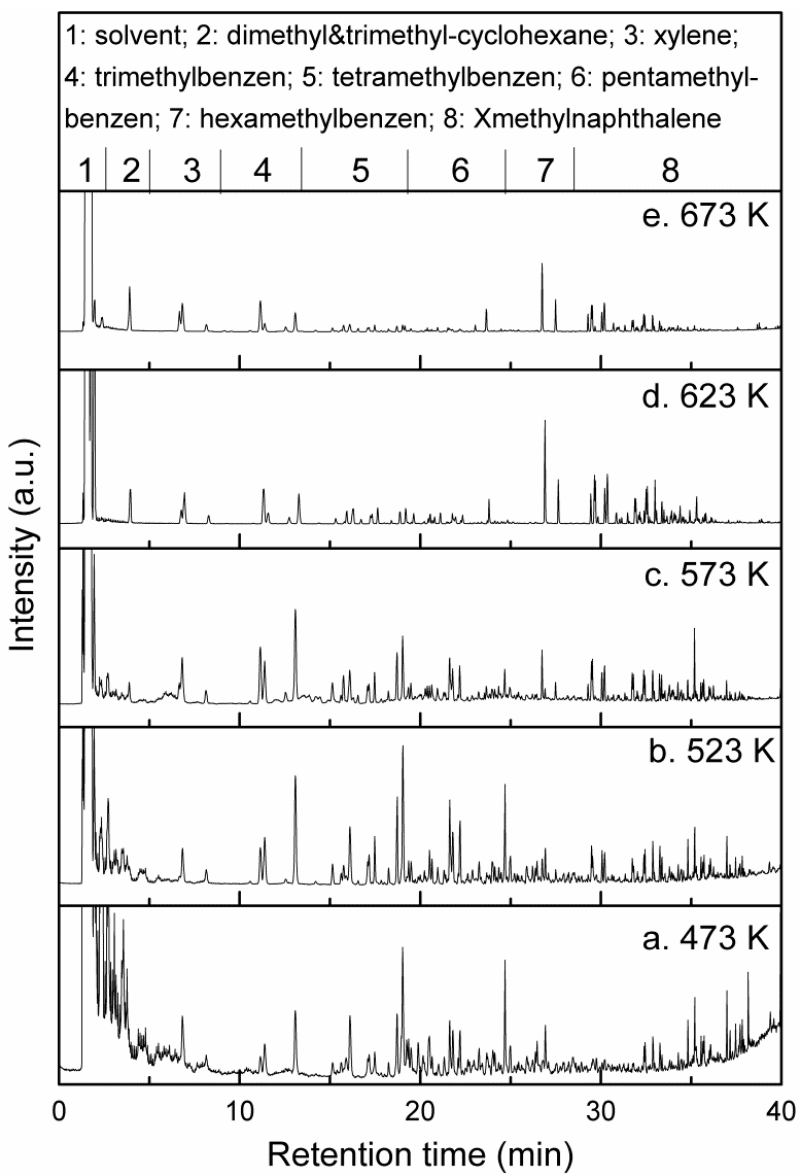

Fig. 10. GC-MS spectra of adsorbates extracted from H-MCM-22 after the adsorption of ethylene at (a) $473 \mathrm{~K}$, (b) $523 \mathrm{~K}$, (c) $573 \mathrm{~K}$, (d) $623 \mathrm{~K}$ and (e) $673 \mathrm{~K}$

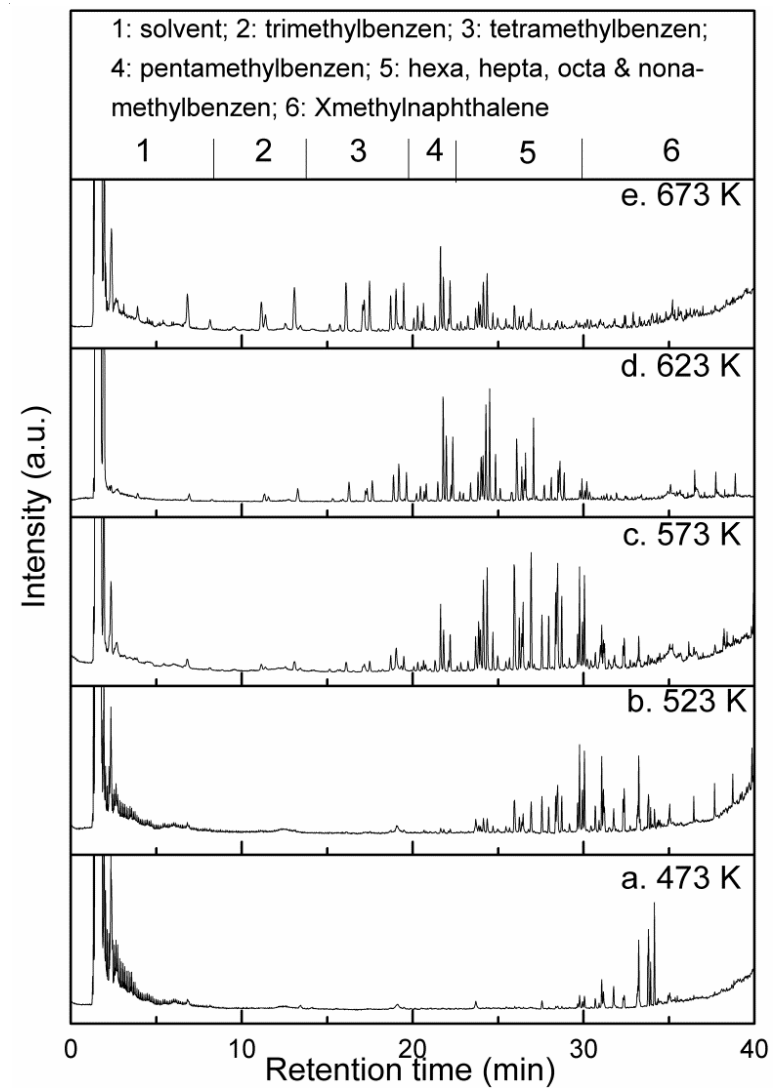

Fig. 11. GC-MS spectra of adsorbates extracted from H-MCM-41 after the adsorption of ethylene at (a) $473 \mathrm{~K}$, (b) $523 \mathrm{~K}$, (c) $573 \mathrm{~K}$, (d) $623 \mathrm{~K}$ and (e) $673 \mathrm{~K}$

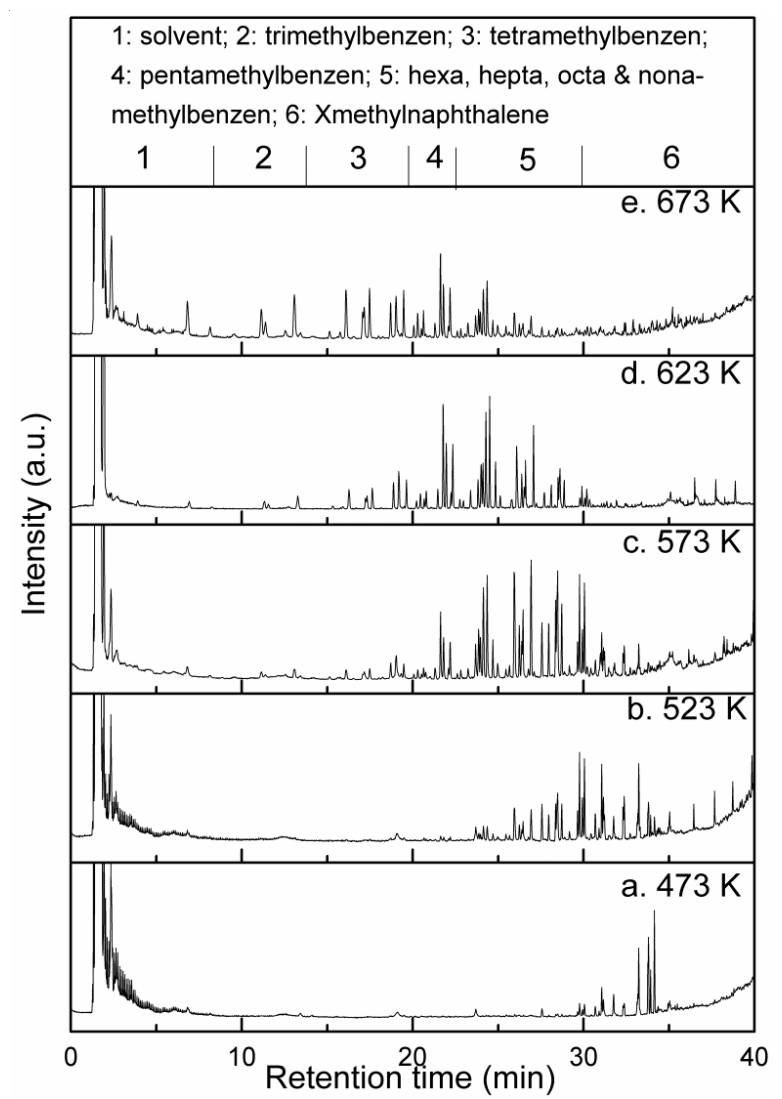

Fig. 12. GC-MS spectra of adsorbates extracted from Na-MCM-41 after the adsorption of ethylene at (a) $473 \mathrm{~K}$, (b) $523 \mathrm{~K}$, (c) $573 \mathrm{~K}$, (d) $623 \mathrm{~K}$ and (e) $673 \mathrm{~K}$ 
Fig. 5 and Fig. 9 show the similar temperature intervals where peak values appear. This phenomenon revealed that the maximum adsorption capacity was proportional to the number of activated acid sites at different temperature. The second peak in Fig. 9a was attributed to the pore system formed by 10 -memebered rings $(0.41 \times 0.51 \mathrm{~nm})$, which would not count for aromatization of ethylene. That is because the pore diameter was too small, even benzene molecule had a kinetic diameter of $0.59 \mathrm{~nm}^{26}$. On the other hand, the rate for ethylene desorption from active sites would rise with the increasing temperature. Ethylene might not be able to dimerize at a certain rapid desorption rate. So the adsorption amount might not enhance all the time with the increasing temperature.

The proportion of the final products with less carbon number increased with the rise of the adsorption temperature (Figs. 10-12). This result could be attributed to the limitation of the pore size to the final products. The aromatization of ethylene took place in the pores which their diameter should be bigger than $0.59 \mathrm{~nm}$ at least. From Fig. 3 we know that the pore size distribution of our adsorbents present a downward trend when it is bigger than $0.59 \mathrm{~nm}$. Confirmed by $\mathrm{NH}_{3}-\mathrm{TPD}$ tests, the number of activated acid sites got larger with the increasing temperature. Meanwhile the pore diameter got smaller with the increasing number of the pores. It means that the proportion of smaller pores which took part in aromatization rose up. So we could observe that the peaks of final products shifted form high carbon number aromatics to low carbon number aromatics.

\section{Conclusion}

In this study, the characterization of pore system for two kinds of molecular sieves was firstly investigated, especially the pore size distribution which played an important role in the analysis of ethylene adsorption. Then the measurements of ethylene adsorption were performed under different temperature. We demonstrated that the adsorption amount of ethylene would not always reduce with the increasing temperature. By means of in situ FTIR of pyridine adsorption, $\mathrm{NH}_{3}-$ TPD and GC-MS we proposed the possible mechanism of the ethylene catalytic aromatization and adsorption at high temperature.

MCM-22 and MCM-41 had different pore size distribution which decided the acid strength distribution. The ion exchange of sodium type of MCM-41 to hydrogen type increased the number of Bronsted acid which was responsible for the aromatization of ethylene. The aromatization of ethylene would not happen since lack of proton affinity energy to start the reaction at room temperature. But with the increasing temperature, more and more pores were activated and able to take part in the reaction. Aromatization of ethylene achieved the improvement of the adsorption amount. $\mathrm{NH}_{3}$-TPD curves and the trend graph of adsorption amount presented similar patterns which means the adsorption capacity were strongly related to the number of acid sites. From the results of GC-MS tests we confirmed the final products of ethylene adsorption were mainly alkyl substitutes of benzene, also alkyl substitutes of cyclohexane and naphthalene were found. By the analysis of compositions of the final products formed at different temperature we demonstrated that the sizes of final adsorbates were limited by the pore diameter.

\section{REFERENCES}

1. W. Malisoff and G. Egloff, J. Phys. Chem., 23, 65 (1919).

2. Chem. Eng. News, 84, 59 (2006).

3. M. Ruth, A.D. Amato and B. Davidsdottir, Environ. Sci. Technol., 36, 119 (2002).

4. D.-R. Park, J.-L. Zhang, K. Ikeue, H. Yamashita and M. Anpo, J. Catal., 185, 114 (1999).

5. J.M. Alonso and A.N. Stepanova, Science, 306, 1513 (2004).

6. A.R. Albunia, T. Minucci and G. Guerra, J. Mater. Chem., 18, 1046 (2008).

7. J.-J. Li, C.-Y. Ma, X.-Y. Xu, J.-J. Yu, Z.-P. Hao and S.-Z. Qiao, Environ. Sci. Technol., 42, 8947 (2008).

8. A.E. Blidi, L. Rigal, G. Malmary, J. Molinier and L. Torres, Food Qual. Prefer., 4, 119 (1993).

9. J. Kim, J. Hazard. Mater., B131, 131 (2006).

10. A.R. Albunia, T. Minucci and G. Guerra, J. Mater. Chem., 18, 1046 (2008).

11. B. Hauchecorne, T. Tytgat, S.W. Verbruggen, D. Hauchecorne, D. Terrens, M. Smits, K. Vinken and S. Lenaerts, Appl. Catal., B, 105, 111 (2011).

12. Y.-M. Fu, L.-Z. Shao, L. Tong and H. Liu, Bioresour. Technol., 102, 576 (2011).

13. S.A. Al-Muhtaseb, J. Chem. Eng. Data, 22, 313 (2010).

14. P.-C. Ye, Z.-H. Fang, B.-G. Su, H.-B. Xing, Y.-W. Yang, Y. Su and Q.- L. Ren, J. Chem. Eng. Data, 22, 5669 (2010).

15. N. Patdhanagul, T. Srithanratana, K. Rangsriwatananon and S. Hengrasmee, Microporous Mesoporous Mater, 131, 97 (2010).

16. N. Sue-Aok, T. Srithanratana, K. Rangsriwatananon and S. Hengrasmee, Appl. Surf. Sci., 256, 3997 (2010).

17. B. Erdogan, M. Sakizci and E. Yörükogullari, Appl. Surf. Sci., 254, 2450 (2008).

18. J.-Y. Shen, J.M. Hill, R.M. Watwe, S.G. Podkolzin and J.A. Dumesic, Catal. Lett., 60, 1 (1999).

19. I.R. Subbotina and V.B. Kazanskii, Kinet. Catal., 43, 115 (2002).

20. J. Yang, Y. Zhou, J.-Y. Yang, W.-G. Lin, Y.-J. Wu, N. Lin, J. Wang and J.-H. Zhu, J. Phys. Chem. C., 114, 9588 (2010).

21. C.T. Kresge, M.E. Leonowicz, W.J. Roth, J.C. Vartuli and J.S. Beck, Nature, 359, 710 (1992).

22. S.L. Lawton, A.S. Fung, G.J. Kennedy, L.B. Alemany, C.D. Chang, G.H. Hatzikos, D.N. Lissy, M.K. Rubin, H.-K. C. Timken, S. Steuernagel and D.E. Woessner, J. Phys. Chem., 100, 3788 (1996).

23. J.S. Beck, J.C. Vartuli, W.J. Roth, M.E. Leonowicz, C.T. Kresge, K.D. Schmitt, C.T.-W. Chu, D.H. Olson, E.W. Sheppard, S.B. McCullen, J.B. Higgins and J.L. Schlenker, J. Am. Chem. Soc., 114, 10834 (1992).

24. B. Chakraborty and B. Viswanathan, Catal. Today, 49, 253 (1999).

25. A.G. Evans, M. Polanyi, H.S. Lilley, L.B. Morgan, H.A. Skinner, P.H. Plesch, M.G. Evans, H.W. Melville, G.B.B.M. Sutherland, W. Cooper, J.H. Baxendale, G. Gee, H.W. Thompson, J.L. Stoves, F. Brown, C.W. Burn, D.J. Crisp and I. MacArthur, J. Chem. Soc., 252 (1947).

26. A. Ogata, D. Ito, K. Mizuno, S. Kushiyama and T. Yamamoto, IEEE Trans. Ind. Appl., 37, 959 (2001). 